\title{
Surface characteristics of and in vitro behavior of osteoblast-like cells on titanium with nanotopography prepared by high-energy shot peening
}

This article was published in the following Dove Press journal:

International Journal of Nanomedicine

28 November 2014

Number of times this article has been viewed

\author{
Zhennan Deng ${ }^{1,2}$ \\ Baodi Yin' \\ Weihong $\mathrm{Li}^{1}$ \\ Jinsong Liu' \\ Jingyuan Yang' \\ Tieli Zheng' \\ Dafeng Zhang' \\ Haiyang $\mathrm{Yu}^{2}$ \\ Xiaoguang $\mathrm{Liu}^{3}$ \\ Jianfeng $\mathrm{Ma}^{\prime}$
}

'School and Hospital of Stomatology, Wenzhou Medical University,

Wenzhou, Zhejiang, People's Republic

of China; ${ }^{2}$ State Key Laboratory of

Oral Diseases, West China Hospital

of Stomatology, ${ }^{3}$ National Engineering

Research Center for Biomaterials,

Sichuan University, Chengdu, Sichuan,

People's Republic of China
Correspondence: Jianfeng Ma

School and Hospital of Stomatology,

Wenzhou Medical University, Wenzhou,

Zhejiang 325027, People's Republic

of China

Email dentmajianfeng@।63.com

Xiaoguang Liu

National Engineering Research Center

for Biomaterials, Sichuan University,

Chengdu, Sichuan, People's Republic

of China

Email342225231@qq.com
Background and methods: Commercial pure titanium with nanotopography was prepared via a high-energy shot-peening (HESP) technique. The surface characteristics were evaluated, and the preliminary cell responses to the nanotopographical surface were investigated.

Results: The nanotopographical surface layer on titanium was successfully processed by HESP. The average nanoscale grains were approximately $60 \mathrm{~nm}$ in diameter and they were nonhomogeneously distributed on the surface. MG-63 cells with an osteogenic phenotype were well adhered and well spread on the nanostructured surface. Compared to the original polished control, the nanotopographical surface highly improved the adhesion, viability, and differentiation of MG-63 cells.

Conclusion: Titanium with nanotopography achieved by HESP has good cytocompatibility and shows promise for dental implant applications.

Keywords: nanotopography, cytocompatibility, titanium, high-energy shot peening

\section{Introduction}

Osseointegration-based dental implants comprise a well-accepted treatment method for complete and partial edentulism. The success rate of this treatment has been reported to be between $90 \%$ and $95 \%$ at 10 years. ${ }^{1}$ However, implant failures still remain in some cases, varying in terms of implantation sites and patients. ${ }^{2}$ The general consensus is that more biocompatible and osteoconductive implants are required 1) in regions of either poor bone quality or lesser bone quantity and 2) for more rapid implant loading. ${ }^{3-6}$

The surface properties of implants, such as their topography, chemistry, and wettability, can directly influence their interactions with cells. ${ }^{7,8}$ The interactions of cells and the extracellular matrix would then directly affect cell responses including adhesion, proliferation, and differentiation. ${ }^{9}$ In this way, the surface properties of implants play an essential role in terms of the cell responses at the bone-implant interface, affecting the osseointegration process. Various surface modification techniques have been developed to improve the implants' biological interface properties, which favor the bioactivity and bioconductivity of implants. ${ }^{10-12}$

Recently, increasing attention has been focused on the topography characteristics of implant materials, especially with respect to changes in nanotopography, due to their clearly dynamic effects on cell interactions at the surfaces and because they alter cell behavior by direct (cell-surface interactions) and indirect (protein-surface interactions) mechanisms when compared to materials with conventional-sized topography. ${ }^{3,4,13}$ At the nanoscale level, the nanotopography could increase the surface energy, thus improving surface wettability to blood, as well as the spreading and binding of fibrin and matrix proteins; this results in the favoring of bone cell attachment and proliferation, 
especially following implantation, which is an important point in the osseointegration process. ${ }^{14}$ However, current surface nanotechnologies are known to be very expensive, technically sensitive, and time consuming. Therefore, alternative methods of creating nanotopographical surfaces are highly desirable. ${ }^{15,16}$

The high-energy shot-peening (HESP) technique is a cold working process used in industry for surface treatment. Peening a surface spreads it plastically, creating plastic deformation and causing changes in the mechanical properties of the surface. Its main application is to avoid the propagation of microcracks across a surface. It has been recently shown that the microstructure of conventional titanium can be significantly refined to yield ultrafine-grained titanium via severe plastic deformation techniques. ${ }^{17}$ Hence, HESP holds potential as a new method that can be applied to prepare nanoscale surfaces for implants at both the laboratory and the industry levels, without using any additional chemicals or complicated synthesis routes.

In the current study, a nanoscale surface of titanium was prepared by HESP to explore the feasibility of using this method for the surface treatment of dental implants. The obtained surface nanostructures of titanium were characterized by scanning electron microscopy (SEM), atomic force microscopy (AFM), and contact angle measurements; then bone cell responses (using a human MG-63 osteosarcoma cell line) on these nanoscale surfaces were evaluated.

\section{Materials and methods Materials}

The raw material used was a commercial pure titanium (grade 2) plate $10 \mathrm{~mm}$ in thickness. A disk of $14 \mathrm{~mm}$ in diameter and $1 \mathrm{~mm}$ in height was obtained from the plate. One side of the disk was mechanically ground using silicon carbide (SiC) paper from P300 to P1200 and was ultrasonically cleaned with a succession of acetone, ethyl alcohol, and deionized water.

\section{Surface preparation}

The polished surface of the disk was processed for HESP in a vibrator generator (Rösler C2*4S-RH; Untermerzbach, Bavaria, Germany), which is commonly used in industry.

The samples were divided into one of two groups, shot peened for 3 minutes or 5 minutes, respectively, with glass beads of 1-mm diameter, in an effort to achieve an optimum combination of nanosized surface roughness, surface area, and associated energy. Following the peening process, it was expected that a very thin region of a microscale - or even nanoscale - structure would be created at the surface of the titanium samples. The obtained samples were named HESP3 and HESP5. Untreated polished titanium samples (p-Ti) were used as control.

\section{Surface microstructure characterization}

The surface of the disks was observed by SEM (JSM5900LV; JEOL, Tokyo, Japan) and AFM (SPM-9600; Shimadzu Corporation, Kyoto, Japan). Observations were made at three different points on the disk surfaces, and average values were calculated.

\section{Surface wettability}

The wettability of the different surfaces was assessed by measuring the water contact angles using a contact angle instrument (SL200B; Solon, Shanghai, People's Republic of China). Three samples from each group were assessed, and two measurements were performed on each sample to evaluate the average contact angle.

\section{Cell culture and morphology}

The MG-63 cells used in this experiment were from a lineage derived from human osteosarcoma. The cells were purchased from the Cell Bank at the Chinese Academy of Sciences, Beijing, People's Republic of China. MG-63 cells were routinely cultured in Dulbecco's Modified Eagle's Medium (Thermo Fisher Scientific, Waltham, MA, USA), supplemented with $100 \mathrm{U} / \mathrm{mL}$ of penicillin, $100 \mu \mathrm{g} / \mathrm{mL}$ of streptomycin, and 10\% fetal bovine serum (FBS); (Thermo Fisher Scientific), and cultured in $25-\mathrm{mL}$ culture bottles in a humidified $5 \% \mathrm{CO}_{2}$ atmosphere at $37^{\circ} \mathrm{C}$. The culture medium was refreshed every 3 days. Before seeding of the cells, the samples containing surface nanostructures and the control samples were sterilized with ethylene oxide at the West China Hospital Affiliated to Sichuan University.

After being cultured on the samples for 1 day, the cells that adhered to the samples were gently washed with phosphate-buffered saline three times, fixed with $2.5 \%$ glutaraldehyde solution for 2 hours at $4{ }^{\circ} \mathrm{C}$, dehydrated through a series of graded ethanol solutions, critical point dried, and then sputter gold coated in vacuum. The samples were observed by SEM to assess the morphologic changes associated with cell attachment and spreading.

\section{Initial cell adhesion and cell viability}

Cells were cultured for 4 hours in 24-well culture plates at an initial seeding density of $5 \times 10^{4}$ cells per well to evaluate the initial cell adhesion. After trypsinization of the attached 
cells, the cell numbers were counted using a hemocytometer. Then, the cell viability was investigated following culture periods of 1 day, 3 days, 5 days, and 7 days using the 3-(4,5-dimethylthiazol-2-yl)-2,5-diphenyl tetrazolium bromide (MTT) colorimetric assay. In the MTT assay, the mitochondrial dehydrogenases of viable cells cleaved the tetrazolium ring of the substrate to yield purple formazan crystals. ${ }^{18}$ The resulting purple solution was spectrophotometrically measured at $570 \mathrm{~nm}$ using a Bio Assay Reader (HTS7000 Plus; PerkinElmer, Inc, Waltham, MA, USA), and the relative intensities were plotted.

\section{Alkaline phosphatase activity}

Alkaline phosphatase (ALP) activity is one of the most widely used markers for the early osteodifferentiation of osteoblasts. ${ }^{19}$ After culture periods of 1 day, 4 days, and 7 days, ALP activity was measured to characterize the normal osteoblast phenotypic response to nanostructured $\mathrm{Ti}$. Adherent cells on the Ti plates were lysed with $0.05 \%$ Triton X-100 (Amresco, Solon, OH, USA) to release intracellular ALP. The lysed solution was incubated with $500 \mu \mathrm{L}$ of ALP substrate solution for 30 minutes at $37^{\circ} \mathrm{C}$. The reaction was terminated by the addition of $250 \mu \mathrm{L}$ of $0.2 \mathrm{~mol} / \mathrm{L} \mathrm{NaOH}$. A colorimetric assay was used to measure the absorbance of the solution at $405 \mathrm{~nm}$. The total protein concentration of the samples was then evaluated using a bicinchoninic acid protein assay kit (Thermo Scientific, Waltham, MA, USA), and the absorbance in each sample was normalized based on the protein content.

\section{Statistical analysis}

The results were expressed as the means \pm standard deviations. For statistical analysis, one-way analysis of variance was performed, followed by the Student-Newman-Keuls posttest using SPSS 16.0 statistical software. A value of $P<0.05$ was considered statistically significant.

\section{Results \\ Surface analysis}

As shown in Figure 1, the gross appearance of the samples was observed. The HESP3 and HESP5 samples were rough and very rough, respectively, whereas the surface of p-Ti was flat and smooth. The microstructures of HESP3, HESP5, and p-Ti, as observed by SEM, are displayed in Figure 2. It can be seen that $\mathrm{p}$-Ti showed a smooth surface (Figure 2A). In contrast, many spherical crown-shaped pits were observed on HESP3 (Figure 2B) and HESP5 (Figure 2C). Moreover, at higher magnifications of SEM, the microstructure of p-Ti clearly showed that it was featureless and it contained small shallow pits and microscratches that followed a relatively identical direction generated by the polishing process, as was expected (Figure 2D). Conversely, the HESP3 samples showed manifested grain refinement and unique micron-scale structures (Figure 2E). Few nanofeatures can be found in the HESP3 group. With the increase in peening time and plastic deformation, a large number of distinct nanocrystals with an average grain size of approximately $60 \mathrm{~nm}$ were observed; the nanocrystals exhibited an inhomogeneous distribution and a clear grain boundary in HESP5 samples, indicating that a nanotopographical surface on titanium was successfully achieved by HESP after a 5-minute shot-peening process (Figure 2F-H). The in vitro cytocompatibility of HESP5 samples with nanotopography was then investigated and compared with that of the p-Ti samples.

Surface roughness parameters were obtained from the AFM analysis (Figure 3), and are described in Table 1. The HESP5 samples showed significantly increasing roughness
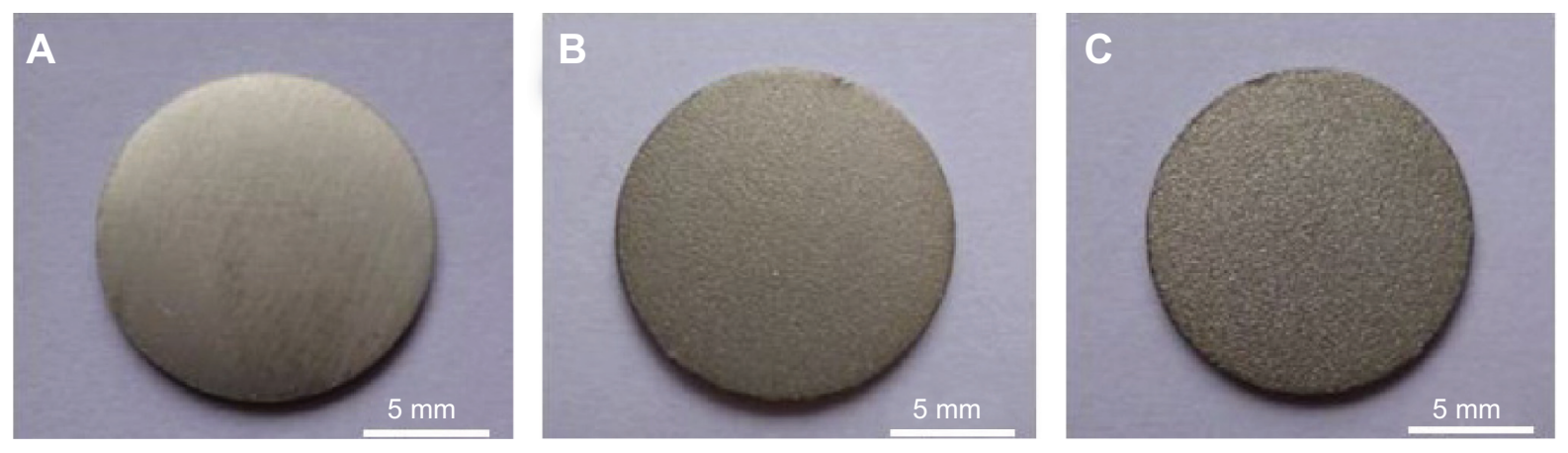

Figure I The gross appearance of the P-Ti (A), HESP3 (B), and HESP5 (C) samples.

Abbreviations: $\mathrm{p}-\mathrm{Ti}$, polished titanium; HESP3, titanium after high-energy shot-peening process for 3 minutes; HESP5, titanium after high-energy shot-peening process for 5 minutes. 

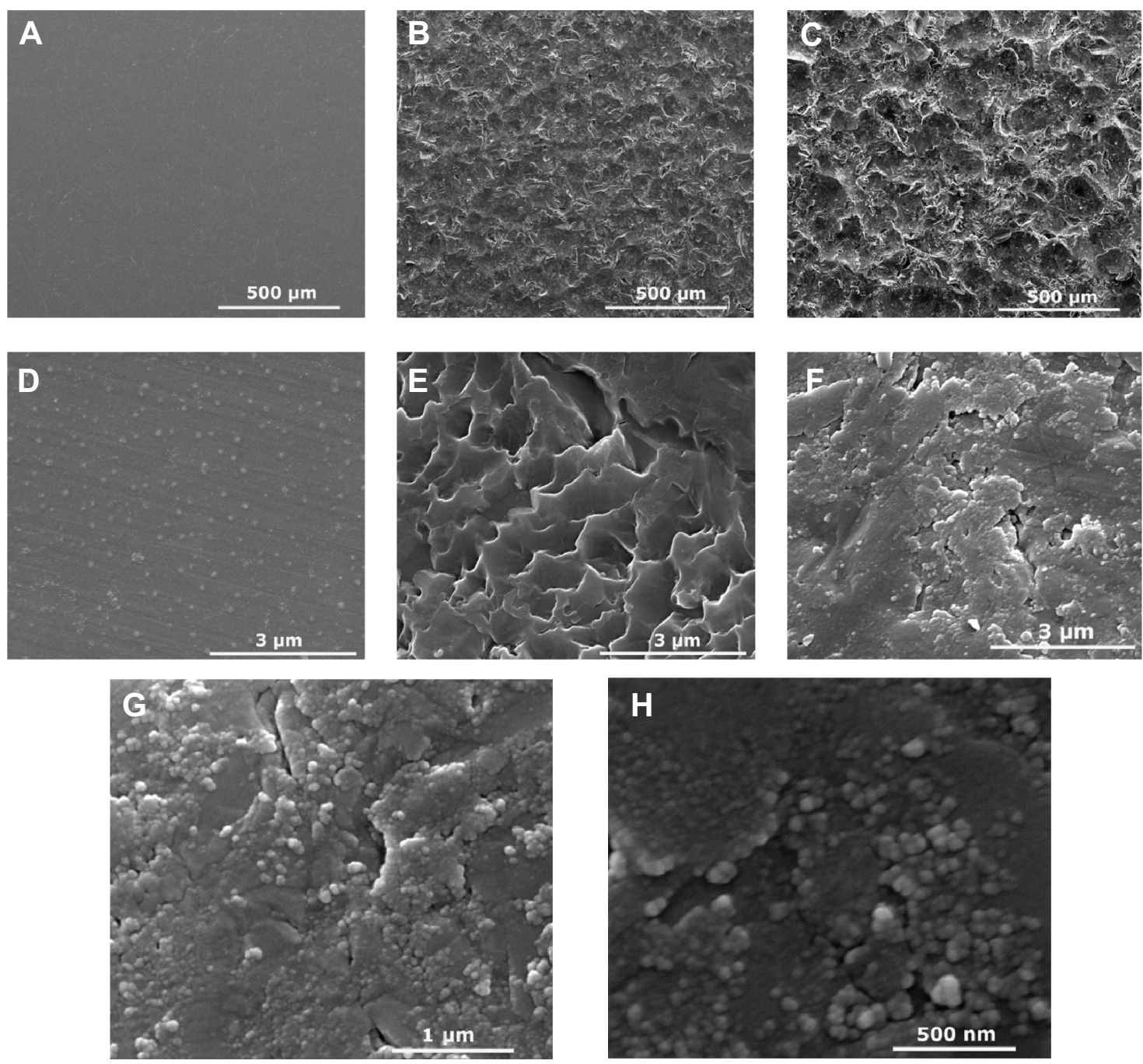

Figure 2 SEM images at low and high magnifications of the P-Ti (A and D), HESP3 (B and E), and HESP5 (C, F-H) surfaces.

Notes: At $\times 80,000$ and $\times 160,000$ magnifications, the $40-\mathrm{nm}$ to $100-\mathrm{nm}$ nanofeatures on the HESP5 surfaces had manifested (G and $\mathbf{H}$ ).

Abbreviations: SEM, scanning electron microscopy; p-Ti, polished titanium; HESP3, titanium after high-energy shot-peening process for 3 minutes; HESP5, titanium after high-energy shot-peening process for 5 minutes.

values $\left(R_{\mathrm{a}}\right.$ and $\left.R_{\mathrm{z}}\right)$, compared with both the $\mathrm{p}$-Ti and HESP3 samples $(P<0.05$; Table 1). Meanwhile, the water contact angle of HESP5 surfaces significantly decreased from $61.6^{\circ} \pm 2.9^{\circ}$ to $40.8^{\circ} \pm 1.7^{\circ}$ compared with that of $\mathrm{p}-\mathrm{Ti}$ $(P<0.05$; Figure 4). There were no significant differences in surface roughness or water contact angle between $\mathrm{p}-\mathrm{Ti}$ and HESP3 surfaces $(P>0.05$; Table 1 and Figure 4$)$.

\section{Cell morphology}

The morphology of the MG-63 cells cultured on HESP5 and p-Ti for 1 day is shown in Figure 5. The cells were well spread on both HESP5 and p-Ti, and they exhibited a spindle-shaped morphology. Moreover, the cells on HESP5 displayed a more widely spread morphology (Figure 5B, D-F) that was highly connected at the surface, and the filopodia were much more discernible and longer when compared with those on $\mathrm{p}-\mathrm{Ti}$ (Figure 5A and C).

\section{Cell adhesion and viability}

After 4 hours of culture, there were significantly more cells adhered on the HESP5 surface than on the p-Ti surface $(P<0.05$; Figure 6A). Figure 6B shows the absorbance of formazan produced by viable cells adhered to both the titanium with nanotopography (HESP5) and the control samples (p-Ti) at days 1, 3, 5, and 7 of culture. The MTT test results showed that the number of cells was not significantly different between the two groups at days 1 and 7 of culture, but a quicker increase in cell quantity on the nanostructured titanium surfaces was evident when compared to the cell quantity on the control 


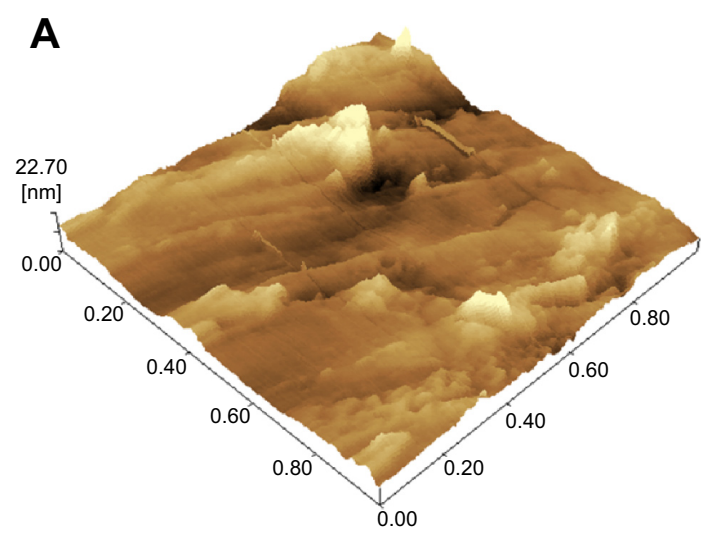

B

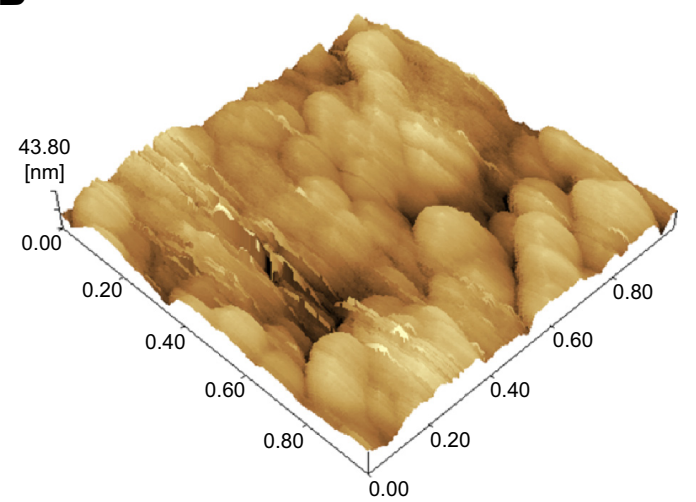

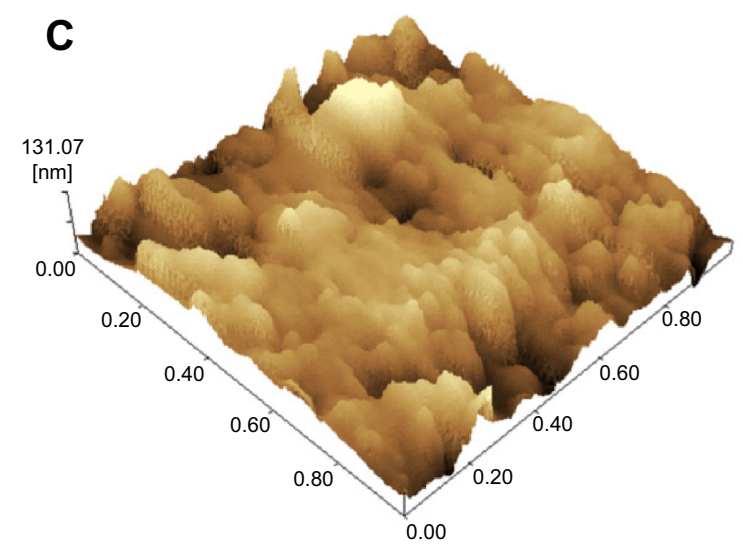

Figure 3 AFM evaluations of the p-Ti (A), HESP3 (B), and HESP5 (C) surfaces.

Abbreviations: AFM, atomic force microscopy; $\mathrm{p}-\mathrm{Ti}$, polished titanium; HESP3, titanium after high-energy shot-peening process for 3 minutes; HESP5, titanium after highenergy shot-peening process for 5 minutes.

samples at days 3 and 5 of culture $(P<0.05)$, suggesting that nanotopography obtained by HESP could be more favorable for the adhesion of cells.

\section{Alkaline phosphatase activity}

The ability of cell differentiation can be estimated by the ALP activity assay. Figure 7 shows that MG-63 cells on HESP5 showed higher ALP levels when compared with those on the polished p-Ti surfaces after 4 days and 7 days of culture,

Table I Surface roughness parameters of $\mathrm{p}-\mathrm{Ti}, \mathrm{HESP} 3$, and HESP5 samples $(n=5)$

\begin{tabular}{lll}
\hline Sample & $\boldsymbol{R}_{\mathrm{a}}(\mathbf{n m})$ & $\boldsymbol{R}_{\mathbf{z}}(\mathbf{n m})$ \\
\hline $\mathrm{P}-\mathrm{Ti}$ & $9.52 \pm 2.64^{\mathrm{a}}$ & $85.3 \mathrm{I} \pm 23.28^{\mathrm{a}}$ \\
$\mathrm{HESP} 3$ & $12.65 \pm 2.88^{\mathrm{a}}$ & $123.32 \pm 27.52^{\mathrm{a}}$ \\
HESP5 & $26.63 \pm 8.60^{\mathrm{b}}$ & $429.3 \mathrm{I} \pm 38.9 \mathrm{I}^{\mathrm{b}}$ \\
\hline
\end{tabular}

Notes: $R_{\mathrm{a}}$ is the absolute arithmetic mean of the contour deviated distance; $R_{\mathrm{z}}$ is the sum of the average of five contour peak heights and the average of five contour bottom depths. ${ }^{a, b}$ The same letters are not significant by the Student-NewmanKeuls posttest at $\alpha=0.05$.

Abbreviations: $\mathrm{p}-\mathrm{Ti}$, polished titanium; HESP3, titanium after high-energy shotpeening process for 3 minutes; HESP5, titanium after high-energy shot-peening process for 5 minutes. and they exhibited a stronger propensity to undergo cell differentiation. There was an average increase in ALP level of $68 \%$ and $24 \%$ in cells on the HESP5 samples, as compared with ALP level of cells on the p-Ti samples, at days 4 and 7 of culture, respectively $(P<0.05)$.

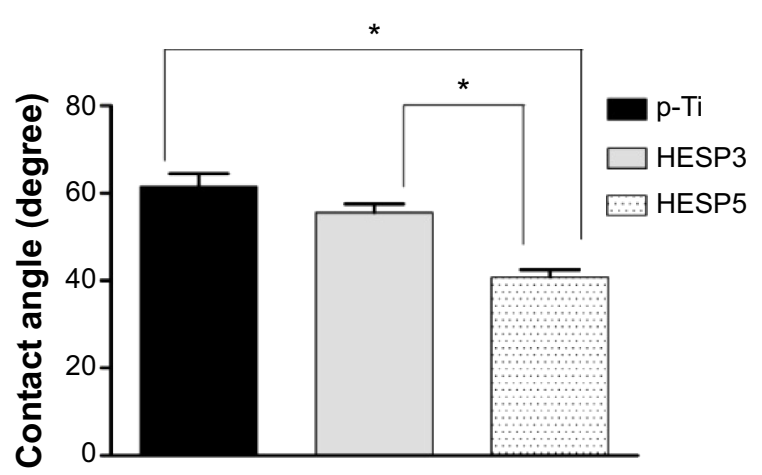

Figure 4 The water contact angles of p-Ti, HESP3, and HESP5 surfaces.

Notes: Data are presented as the mean \pm standard deviation $(n=6) . * P<0.05$, compared with HESP5 samples.

Abbreviations: p-Ti, polished titanium; HESP3, titanium after high-energy shotpeening process for 3 minutes; HESP5, titanium after high-energy shot-peening process for 5 minutes. 

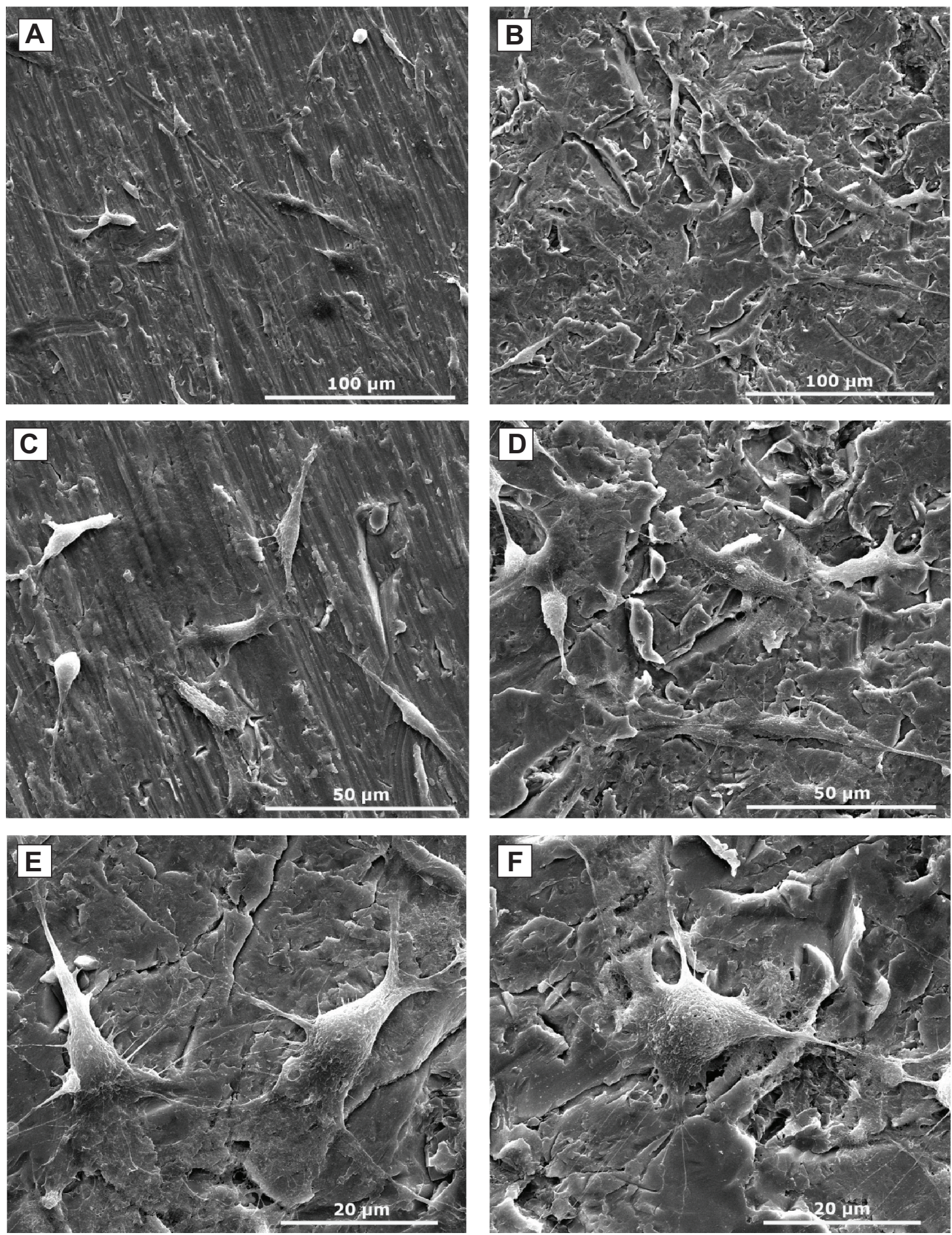

Figure 5 SEM images showing the morphology of cells spread on p-Ti (A and C) and HESP5 (B, D-F) at day I of incubation at both low and high magnifications. Notes: Original magnifications: $\times 1200(\mathbf{A}$ and B); $\times 2400(\mathbf{C}$ and D); $\times 5000$ (E and F).

Abbreviations: SEM, scanning electron microscopy; p-Ti, polished titanium; HESP5, titanium after high-energy shot-peening process for 5 minutes.

\section{Discussion}

Surface nanocrystallization is a new concept that has been proposed for the formation of nanotopography on the surface layer of materials. ${ }^{20}$ It has been demonstrated that materials with nanotopography have unusual and extraordinary mechanical properties and biocompatibilities that are fundamentally different from, and often far superior to, those of their conventional coarse-grained counterparts. ${ }^{15,20}$

It has been found in this study that distinct nanofeatures were successfully created on the surface of titanium by HESP. 
A

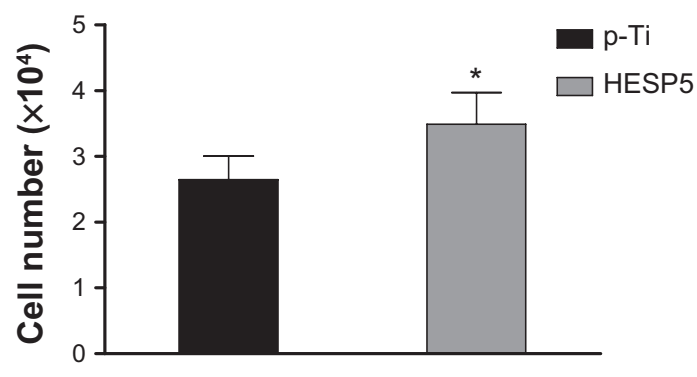

B

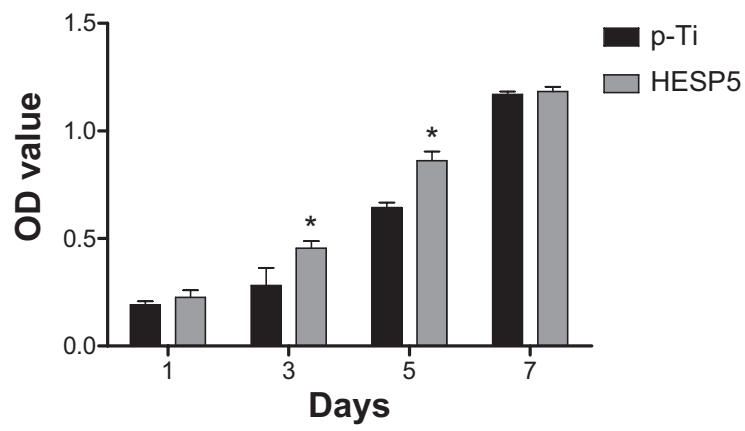

Figure 6 The number of adhered cells on different Ti surfaces at 4 hours of culture (A) and cell viability on different Ti surfaces at days I, 3, 5, and 7 of culture (B). Notes: Data are presented as the mean \pm standard deviation ( $n=5$ per group for the cell adhesion assay; $n=7$ per group for the cell viability assay). $* P<0.05$ compared with $\mathrm{p}-\mathrm{Ti}$.

Abbreviations: OD, optical density; p-Ti, polished titanium; HESP5, titanium after high-energy shot-peening process for 5 minutes.

The formation of nanosized grains is attributed to the great amount of deformation being introduced onto the surface of the Ti samples within a very short period. In addition, the original coarse grains were gradually divided by dislocation walls and dislocation tangles. ${ }^{15}$ According to the SEM and AFM results of HESP 3 and HESP5 samples, and in accordance with previous studies, ${ }^{15,21,22}$ the specific surface nanocrystallization process induced by HESP may occur as follows. At first, some of the dislocations intersect and the stress field at the initial point of deformation is formed. Then, mechanical twinning is induced when the stress increases to the resolved shear limit. With increase of the twin system and enhancement of the twin intersections, grains are refined. Finally, nanosized grains with equiaxed shapes and random crystallographic orientation form under much greater strain, with a high strain rate and multidirectional repeated loads..$^{21,22}$

In the traditional shot-peening technique commonly used in industry, the surface layer microstructure is not refined to

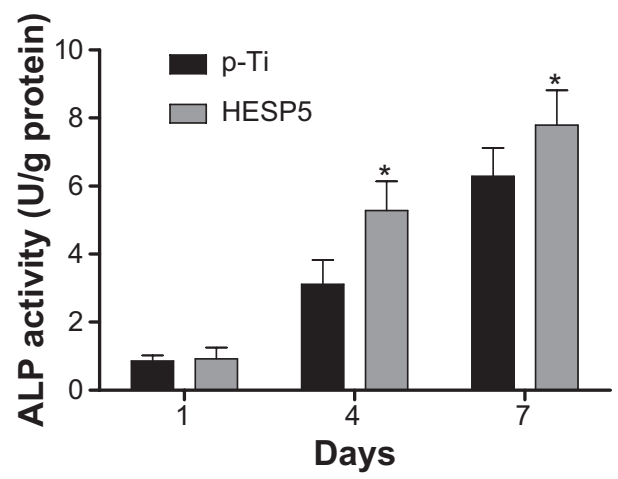

Figure 7 ALP activity of the MG-63 cells on different Ti surfaces after I day, 4 days, and 7 days of culture.

Notes: Data are presented as the mean \pm standard deviation ( $n=7$ per group). Cells growing on HESP5 showed higher ALP activity after 4 days and 7 days of culture when compared with those on the original $\mathrm{p}-\mathrm{Ti}$. $* \mathrm{P}<0.05$.

Abbreviations: ALP, alkaline phosphatase; $\mathrm{p}-\mathrm{Ti}$, polished titanium; HESP5, titanium after high-energy shot-peening process for 5 minutes. nanosizes due to the low microstrain rate, the magnitude of low peening pressure, and the low coverage rate. ${ }^{23}$ However, the peening parameters have been optimized through our preliminary experiments; as such, high peening pressure, $100 \%$ coverage rate, and bigger pills of shot peening were used so that a large amount of twins with different orientations appeared on the surface layer, and the twin insertion could induce nanocrystallization.

In the current study, titanium with nanoscale topography was cocultured with MG-63 cells to evaluate the effects of nanotopography on cell behavior. The results indicated that after 1 day of culture, the cells spread well and presented with a more widely spread morphology on the HESP5 surface than on the $\mathrm{p}$-Ti surface; moreover, a greater number of cells was also observed on the HESP5 samples $(P<0.05)$. In addition, the ALP activity of MG-63 cells increased over time and was significantly higher in cells on the HESP5 samples than in cells on the p-Ti samples at days 4 and $7(P<0.05)$. In this way, it was determined that HESP processing of titanium which was initially only intended as a means for improving titanium's mechanical properties - also produces an effect that holds extraordinary significance for the potential applications of titanium as an implant material, namely, the favorable cytocompatibility of osteoblast cells.

To our knowledge, this promising effect of the nanotopography by HESP on osteoblast responses can be illustrated as follows. The nanoscale topography is a useful way to change the surface roughness and wettability. ${ }^{13,20}$ After HESP treatment, the surface roughness and wettability were improved significantly. The increased surface roughness was found to facilitate the adhesion of biomacromolecules and cells. ${ }^{24}$ Together with surface roughness, surface wettability is an important factor influencing osteoblast cell responses to implant surfaces. It has been confirmed that an increased 
initial hydrophilicity could improve early bone healing response at the cell-biomaterial interface by increasing absorption of adhesive proteins, such as fibronection, collagen, and laminin. Enhancing the number of absorbed adhesive proteins could induce increased osteoblast adhesion by recognition of integrins located on the cellular membrane. ${ }^{14}$

Titanium surfaces with microtopography and additional submicrotopography have been shown to promote early development of the mineralized matrix, which is occasionally observed on the surfaces presenting with microtopography and absent on machined surfaces. ${ }^{25,26}$ The cellular behavior is also influenced by surfaces with nanotopography. Recent studies ${ }^{3,27,28}$ have shown that surfaces with micro- and nanoscale topography are more conducive to the proliferation of bone cells and to the formation of bone of good quality and at good quantity. The complex interactions in the cell-matrix substrate and in cell signaling events have been confirmed at the nanoscale..$^{29,30}$ Different signaling pathways regulate adhesion, migration, differentiation, and gene expression in osteoblasts. ${ }^{31}$ Thus, it has been shown previously that different nanotopographical surfaces influence protein adsorption, cell adhesion, cell proliferation, and synthesis differently, as well as the secretion of extracellular matrix molecules in vitro. ${ }^{27,28}$ The results presented in this study are consistent with those of recent and related studies, ${ }^{27,28}$ which show that topography at the nanoscale level definitely has a positive effect on osteoblast adhesion, viability, and differentiation, thus influencing the bone cell response as it comes in contact with a titanium substrate.

In light of the aforementioned roles of the different parameters that affect cell behavior, the observed favorable bone cell behavior on the shot-peened surface can be concluded to be the net result of the surface nanostructure's effectiveness in promoting bone cell responses. Further in-depth biological studies (which we are planning to conduct) will be performed to investigate the mechanisms that control the enhancement of cell responses caused by the nanotopographical surface obtained via HESP treatment.

Thus, this investigation illustrated that there is great potential for this novel process of surface modification. Specially, the attractiveness of this method in enhancing the bone cell responses is an added benefit when combined with the mechanical properties of the titanium implant that this method produces, which is not offered by other techniques.

\section{Conclusion}

It has been shown that the nanotopography of titanium can be successfully prepared by the HESP technique. Our in vitro study results verify that nanostructured titanium is beneficial for osteoblast responses such as cell adhesion, cell viability, and cell differentiation. We believe that the application of nanocrystallization by HESP on implant surfaces is feasible in clinical practice. Titanium with nanotopography created by HESP is confirmed as a good candidate for improving the biocompatibility of the dental implant.

\section{Acknowledgments}

This study was supported by grants from the National Natural Science Foundation of China (81371182 and 81100782), the Zhejiang Provincial Natural Science Foundation of China (Y2110400), and the Wenzhou Municipal Science and Technology Bureau Foundation of China (Y20140112).

\section{Disclosure}

The authors report no conflicts of interest in this work.

\section{References}

1. Diz P, Scully C, Sanz M. Dental implants in the medically compromised patient. J Dent. 2013;41(3):195-206.

2. Steigenga JT, Al-Shammari KF, Nociti FH, et al. Dental implant design and its relationship to long-term implant success. Implant Dent. 2003; 12(4):306-317.

3. Xia L, Feng B, Wang P, et al. In vitro and in vivo studies of surfacestructured implants for bone formation. Int J Nanomedicine. 2012;7: 4873-4881.

4. Cheng Y, Wu J, Gao B, et al. Fabrication and in vitro release behavior of a novel antibacterial coating containing halogenated furanone-loaded poly(L-lactic acid) nanoparticles on microarc-oxidized titanium. Int $J$ Nanomedicine. 2012;7:5641-5652.

5. Chen WC, Ko CL. Roughened titanium surfaces with silane and further RGD peptide modification in vitro. Mater Sci Eng C Mater Biol Appl. 2013;33(5):2713-2722.

6. Wang Z, Sun Y, Wang D, Liu H, Boughton RI. In situ fabrication of silver nanoparticle-filled hydrogen titanate nanotube layer on metallic titanium surface for bacteriostatic and biocompatible implantation. Int J Nanomedicine. 2013;8:2903-2916.

7. Deligianni DD, Katsala N, Ladas S, Sotiropoulou D, Amedee J, Missirlis YF. Effect of surface roughness of the titanium alloy Ti6$\mathrm{Al}-4 \mathrm{~V}$ on human bone marrow cell response and on protein adsorption. Biomaterials. 2001;22(11):1241-1251.

8. Lamers E, Walboomers XF, Domanski M, et al. The influence of nanoscale grooved substrates on osteoblast behavior and extracellular matrix deposition. Biomaterials. 2010;31(12):3307-3316.

9. Novaes AB Jr, de Souza SL, de Barros RR, et al. Influence of implant surfaces on osseointegration. Braz Dent J. 2010;21(6):471-481.

10. Kim KH, Ramaswamy N. Electrochemical surface modification of titanium in dentistry. Dent Mater. 2009;28(1):20-36.

11. Forster Y, Rentsch C, Schneiders W, et al. Surface modification of implants in long bone. Biomatter. 2012;2(3):149-157.

12. Zhang W, Li Z, Liu Y, et al. Biofunctionalization of a titanium surface with a nano-sawtooth structure regulates the behavior of rat bone marrow mesenchymal stem cells. Int J Nanomedicine. 2012;7:4459-4472.

13. Jindal S, Bansal R, Singh BP, et al. Enhanced osteoblast proliferation and corrosion resistance of $\mathrm{c} p$-Ti through surface nanostructuring by ultrasonic shot peening and stress relieving. J Oral Implantol. 2014; 40(suppl 1):347-355. 
14. Dohan Ehrenfest DM, Coelho PG, Kang BS, Sul YT, Albrektsson T. Classification of osseointegrated implant surfaces: materials, chemistry and topography. Trends Biotechnol. 2010;28(4):198-206.

15. Lu K, Lu J. Nanostructured surface layer on metallic materials induced by surface mechanical attrition treatment. Mater Sci Eng. 2004;375-377: 38-45.

16. Ballo A, Agheli H, Lausmaa J, Thomsen P, Petronis S. Nanostructured model implants for in vivo studies: influence of well-defined nanotopography on de novo bone formation on titanium implants. Int J Nanomedicine. 2011;6:3415-3428.

17. Yao ZQ, Ivanisenko Y, Diemant T, et al. Synthesis and properties of hydroxyapatite-containing porous titania coating on ultrafine-grained titanium by micro-arc oxidation. Acta Biomater. 2010;6(7):2816-2825.

18. Serrano MC, Pagani R, Vallet-Regí M, et al. In vitro biocompatibility assessment of poly(epsilon-caprolactone) films using L929 mouse fibroblasts. Biomaterials. 2004;25(25):5603-5611.

19. Sibilla P, Sereni A, Aguiari G, et al. Effects of a hydroxyapatite-based biomaterial on gene expression in osteoblast-like cells. J Dent Res. 2006;85(4):354-358.

20. Lu K, Lu J. Surface nanocrystallization (SNC) of metallic materials: presentation of the concept behind a new approach. J Mater Sci Tech. 1999;15:193-197.

21. Pi Y, Agoda-Tandjawa G, Potiron S, Demangel C, Retraint D, Benhayoune H. Surface nanocrystallization of Ti-6Al-4V alloy: microstructural and mechanical characterization. JNanosci Nanotechnol. 2012; 12(6):4892-4897.

22. Aliofkhazraei M, Rouhaghdam AS. Formation of nanocrystalline layers by surface severe plastic deformation and pulsed plasma electrolytic carburizing. J Nanosci Nanotechnol. 2010;10(7):4777-4781.
23. Ma G, Luo Y, Chen C. Surface nanocrystallization of commercial pure titanium by shot peening. Trans Nonferrous Met Soc China. 2004; 14(special 2):204-209.

24. Bang SM, Moon HJ, Kwon YD, Yoo JY, Pae A, Kwon IK. Osteoblastic and osteoclastic differentiation on SLA and hydrophilic modified SLA titanium surfaces. Clin Oral Implants Res. 2014;25(7):831-837.

25. Schwartz Fo HO, Novaes AB Jr, de Castro LM, Rosa AL, de Oliveira PT. In vitro osteogenesis on a microstructured titanium surface with additional submicron-scale topography. Clin Oral Implants Res. 2007;18(3):333-344.

26. Raimondo T, Puckett S, Webster TJ. Greater osteoblast and endothelial cell adhesion on nanostructured polyethylene and titanium. Int $J$ Nanomedicine. 2010;5:647-652.

27. Oshida Y, Tuna EB, Aktoren O, Gencay K. Dental implant systems Inter J Mol Sci. 2010;11(4):1580-1678.

28. Puckett S, Pareta R, Webster TJ. Nano rough micron patterned titanium for directing osteoblast morphology and adhesion. Int J Nanomedicine. 2008;3(2):229-241

29. de Oliveira PT, Zalzal SF, Beloti MM, Rosa AL, Nanci A. Enhancement of in vitro osteogenesis on titanium by chemically produced nanotopography. J Biomed Mater Res A. 2007;80(3):554-564.

30. de Oliveira PT, Nanci A. Nanotexturing of titanium-based surfaces upregulates expression of bone sialoprotein and osteopontin by cultured osteogenic cells. Biomaterials. 2004;25(3):403-413.

31. Schneider GB, Zaharias R, Stanford C. Osteoblast integrin adhesion and signaling regulate mineralization. J Dent Res. 2001;80(6):1540-1544.
International Journal of Nanomedicine

\section{Publish your work in this journal}

The International Journal of Nanomedicine is an international, peerreviewed journal focusing on the application of nanotechnology in diagnostics, therapeutics, and drug delivery systems throughout the biomedical field. This journal is indexed on PubMed Central, MedLine, CAS, SciSearch $®$, Current Contents $\AA /$ Clinical Medicine,

\section{Dovepress}

Journal Citation Reports/Science Edition, EMBase, Scopus and the Elsevier Bibliographic databases. The manuscript management system is completely online and includes a very quick and fair peer-review system, which is all easy to use. Visit http://www.dovepress.com/ testimonials.php to read real quotes from published authors. 